\title{
Using data to advance Employment First: Opportunities and direction
}

\author{
Derek Nord* and Teresa Grossi \\ Indiana Institute on Disability and Community, Indiana University, Bloomington, IN, USA
}

Revised/Accepted November 2018

\begin{abstract}
.
BACKGROUND: The continued advancement of Employment First requires, in part, a strong understanding about our existing policies and practices and how effective systems are as they undergo changes. Data about the employment of people with disabilities and about employment support systems are a critical component to this advancement.

OBJECTIVE: This paper presents an overview of the current national context as it relates to the employment of people with disabilities.

CONCLUSION: Next a discussion about the importance of employment data and key data-centric opportunities for the field are presented. A summary of important data innovations occurring nationally are offered to highlight opportunities that may exist in other states. Finally, the authors present a brief discussion on how to advance the field's use of these critical data.
\end{abstract}

Keywords: Employment First, employment, disability, data

\section{Introduction}

Much progress has been made, in recent years, to raise the importance of employment in the lives of people with disabilities. The Employment First movement has been a catalyst for systems change that has spread across the country seeking to elevate stakeholder expectations and remove system barriers to individual employment in the community (Nord, Hamre, Pettingell, \& Magiera, 2018; Association of People Supporting Employment First, 2017; Nord \& Parent-Johnson, 2018). The federal landscape has also evolved with the passage and ongoing implementation of the Workforce Innovation and Opportunity Act (WIOA) (Pub. L. 113-128) and Medicaid Home and Community-Based Services (HCBS) settings rule that requires states to ensure employment services are integrated in and support full access to the

\footnotetext{
*Address for correspondence: Derek Nord PhD, Indiana Institute on Disability and Community, Indiana University, 1905 North Range Rd., Bloomington, IN 47408, USA. Tel.: +1 812855 7102; E-mail: dnord@indiana.edu.
}

greater community (Centers for Medicare \& Medicaid Services, 2014).

As a field, vocational rehabilitation and related disciplines have lengthy histories of using employment and systems data to inform policies, practices and systems of support that affect people with disabilities. As a result of these efforts, a great deal is understood about the employment of people with disabilities in competitive settings, providing a multidimensional understanding. Research has shown that people with disabilities are grossly underrepresented in the labor force compared to the general population (Kessler Foundation \& University of New Hampshire, 2018). When in the labor force looking for work or employed, people with disabilities tend to experience unemployment at nearly twice the rate as those without disabilities (Butterworth et al., 2016). Research has also shown that systems of support, such as Vocational Rehabilitation (VR) and Medicaid HCBS, play an important role in facilitating employment outcomes (Butterworth et al., 2016). Though the delivery of employment supports 
vary on a state-by-state basis (Plotner, Trach, Oertle, \& Fleming, 2014), some services and systemic approaches relate to significantly better employment outcomes (Nord \& Hepperlen, 2016; Nord et al., 2018). Research has also shown where systems are challenged in achieving quality outcomes for those they serve. For example, we know that employment support and outcome disparities exist in the Medicaid HCBS system for those that have more significant disabilities (Nord et al., 2018). Racial disparities have also been found related to VR outcomes (Olney \& Kennedy, 2002).

\subsection{Existing data opportunities}

As the field engages in systems change initiatives and continued advancement of the Employment First movement, it is important to take stock of the existing data assets available. Such resources can aid in the ongoing monitoring and evaluation of state and national initiatives, as well as provide critical information for policy makers and employment advocates. To use existing data resources in such a manner, however, requires the potential users to first understand what data is available and then understand how the resource can be leveraged. Many resources exist and the following are a few examples of existing data resources available to the public.

\subsubsection{U.S. Census Bureau, American Community Survey (ACS)}

The ACS provides robust nationally representative data on various topics, including disability and employment. The data program enables community leaders and advocates the opportunity to analyze data at national, state, and local-levels. The U.S. Census Bureau provides users an easy to use platform, making much of the data accessible by way of a web-based platform. Public use datasets can be drawn for more sophisticated analysis.

\subsubsection{National Core Indicators (NCI)}

The NCI (www.nationalcoreindicators.org) is an ongoing data collection program for state, public developmental disabilities agencies administered by Human Services Research Institute (HSRI) and the National Association for State Directors of Developmental Disabilities Services (NASDDDS). With nearly every state participating, the program provides an assessment of services and outcomes to people with intellectual and developmental disabilities. The primary purpose of the NCI data program is to support states in evaluating and improving services. The program also allows public access to some of the state data through its online data platform, allowing for comparisons across states and overtime.

\subsubsection{StateData: The national report on employment services and outcomes}

The national report provides an annual assessment of employment services and supports utilization and outcomes for people with intellectual and developmental disabilities. The report utilizes aggregate data to provide national and state pictures of the various employment systems, including VR and HCBS. Found at www.statedata.info, the report can be downloaded and users can build custom data charts and tables.

\subsection{Employment data innovation}

Employment and disability is complex and a multidimensional story that intersects with other major domains of life, such as health and wellness, relationships, education, and economic well-being (Nord et al., 2015). It also is a story about social justice and equality. As a community of researchers, analysts, evaluators, and advocates, it is imperative that innovation in the data space occurs to ensure the continual advancement of what is known about employment for people with disabilities, as well as the effectiveness or ineffectiveness of policies and practices. Today's data rich and technologically advanced environment provides a unique opportunity to do this by providing more sophisticated understandings and more widely accessible analyses.

A number of opportunities do exist and would further advance employment for people with disabilities if expanded. First and foremost, collecting new and more granular data on employment systems, system users and their outcomes is necessary. Currently, much of what is known related to employment systems is a high-level, aggregate perspective. Though important, such data is limited in its ability to describe individual experiences within systems. To understand what people with disabilities experience, it is necessary to gather individual-level data. The Day and Employment Services Outcomes Systems (DESOS) program conducted in Indiana by the Indiana Institute on Disability and Community is an example of an effective state-wide mechanism to collect information about employment service users. This survey program is able to capture background information about each person with a disability, details about the 
employment, other services utilized, and employment and non-employment outcomes. These data are then linked to the employment provider. As a data program that has been in operation since 2002, it allows for an ongoing assessment of Indiana's employment system overtime by highlighting changes, barriers, and strengths, thus allowing state leaders and support providers critical information to support systems and policy improvement and change at both the state and local levels.

Existing datasets also present a unique opportunity for data innovation. Many systems of support, such as a state's Medicaid HCBS or VR programs, collect a wealth of data on service utilization, reimbursement, and service outcomes. Outside of the human services and disability systems, many other state agencies collect data on individuals within that state system. With proper state leadership and authority, a clear purpose, and the skills to implement, it is possible to connect the various state data to inform and improve disability employment support programs and outcomes. Many states have implemented such initiatives. In Minnesota, the Department of Human Services successfully linked Medicaid service utilization data to the state's unemployment insurance data, allowing the state to understand the earnings of those receiving HCBS employment services across the various settings. Other states have found ways to link Medicaid, VR, and education data to better understand transition and post-school outcomes as it relates to employment.

\subsection{Moving the field forward}

To expand the field's understandings, improve services, and more effectively support advocacy efforts, data plays an important role. As a community of employment researchers, evaluators, and advocates, we have a responsibility to work closely with key decision-makers of employment services and supports to understand this importance so data needs are known and planned for in a deliberate, proactive manner. Unfortunately, data analysis and dataset development can be overly complex tasks requiring specialized skills. Thus, as a field, we have a responsibility to support the technical skills required to support such initiatives. This may include developing the specialized skills or grooming the skill in others, so as to be a resource to others in the state. Finally, we have a responsibility to make the data and analyses accessible to a diverse group of audiences, including people with disabilities and their allies.

\section{Conclusion}

The continued advancement of policies and practices that make employment for people with disabilities a reality requires a multipronged approach. A key element is the use of data to tell the powerful story that people with disabilities can work and want to work. As a field, we are fortunate to have a wealth of data, technological, and human resources to contribute to this narrative. By leveraging these assets, employment for people with disabilities can take a more prominent role in our national discourse.

\section{Acknowledgments}

This publication was developed under grants from the Administration on Intellectual and Developmental Disabilities (AIDD grant number 90DDUC001), Administration for Community Living (ACL), U.S. Department of Health and Human Services (HHS). The contents of this article do not necessarily represent the policy of AIDD, ACL, HHS, and you should not assume endorsement by the Federal Government.

\section{Conflict of interest}

None to report.

\section{References}

Association of People Supporting Employment First. (2017). APSE Employment First statement. Rockville, MD: Author. Retrieved from http://apse.org/employment-first/statement/

Butterworth, J., Winsor, J., Smith, F. A., Migliore, A., Domin, D., Timmons, J. C., \& Hall, A. C. (2016). StateData: The national report on employment services and outcomes. Boston, MA: Institute for Community Inclusion. Retrieved from https://www.statedata.info/sites/statedata.info/files/files/state_ data_book_2015.pdf

Centers for Medicare \& Medicaid Services. (2014). Fact sheet: Summary of key provisions of the 1915(c) Home and Community-Based Services (HCBS) waivers final rule. Washington, DC: Author. Retrieved from https://www. medicaid.gov/medicaid/hcbs/downloads/1915c-fact-sheet.pdf

Kessler Foundation \& University of New Hampshire. (2018). nTIDE October 2018 jobs report: Rise in indicators extends positive trend for Americans with disabilities. Durham, NH: Author. Retrieved from https://researchondisability.org/home/ ntide/ntide-news-item/2018/11/02/ntide-october-2018-jobs-re port-rise-in-indicators-extends-positive-trend-for-americanswith-disabilities 
Nord, D., Barkoff, A., Butterworth, J., Carlson, D., Cimera, R., Fabian, E.,.. . \& Wohl, A. (2015). The 2015 national goals for employment economic self-sufficiency for people with IDD. Inclusion, 3(4), pp. 227-233.

Nord, D., Hamre, K., Pettingell, S., \& Magiera, L. (2018). Effect of employment goals and guardianship on employment settings. Research and Practice for Persons with Severe Disabilities. doi: 10.1177/1540796918785352

Nord, D. \& Hepperlen, R. (2016). More job services - better employment outcomes: Increasing job attainment for people with IDD. Intellectual and Developmental Disabilities, 54(6), 402-411.
Nord, D. \& Parent-Johnson, W. (2018). Employment First. In Disability in American Life: An Encyclopedia of Concepts, Policies, and Controversies. Santa Barbara, CA: ABC-CLIO.

Olney, M. F. \& Kennedy, J. (2002). Racial disparities in VR use and job placement rates for adults with disabilities. Rehabilitation Counseling Bulletin, 45(3), 177-185. http://dx.doi.org/ 10.1177/003435520204500307

Plotner, A. J., Trach, J. S., Oertle, K. M., \& Fleming, A. R. (2014). Differences in service delivery between transition VR counselors and general VR counselors. Rehabilitation Counseling Bulletin, 57(2), 109-115. https://doi.org/10.1177/0034355213 499075 